\title{
Halogen Bonding in 2,5-Dichloro-1,4-benzoquinone: Insights from Experimental and Theoretical Charge Density Analysis
}

\section{Published as part of the Crystal Growth \& Design virtual special issue on Halogen Bond in Crystal Engineering: Fundamentals and Applications}

Venkatesha R. Hathwar, ${ }^{\dagger}$ Rajesh G. Gonnade, ${ }^{\ddagger}$ Parthapratim Munshi, ${ }^{\S}$ Mohan M. Bhadbhade, ${ }^{\neq, \perp}$ and Tayur N. Guru Row,

${ }^{+}$Solid State and Structural Chemistry Unit, Indian Institute of Science, Bangalore 560012, India

${ }^{\ddagger}$ Center for Materials Characterization, National Chemical Laboratory, Pune 411008, India

${ }^{\S}$ Laboratoire de Crystallographie, Resonance Magnetique \& Modelisation, CRM2, CNRS, UMR 7036, Nancy Université,

Faculté des Sciences et Techniques, BP 70239, 54506 Vandoeuvre-lès-Nancy CEDEX, France

${ }^{\perp}$ Mark Wainwright Analytical Center, University of New South Wales, Sydney, Australia, NSW 2052

ABSTRACT: Experimental charge density distribution in 2, 5-dichloro-1, 4-benzoquinone has been carried out using high resolution X-ray diffraction data at $90 \mathrm{~K}$ to quantitatively evaluate the nature of $\mathrm{C}-\mathrm{Cl} \cdots \mathrm{O}=\mathrm{C}$ halogen bond in molecular crystals. Additionally, the halogen bond is studied from geometrical point of view and the same has been visualized using Hirshfeld surface analysis. The obtained results from
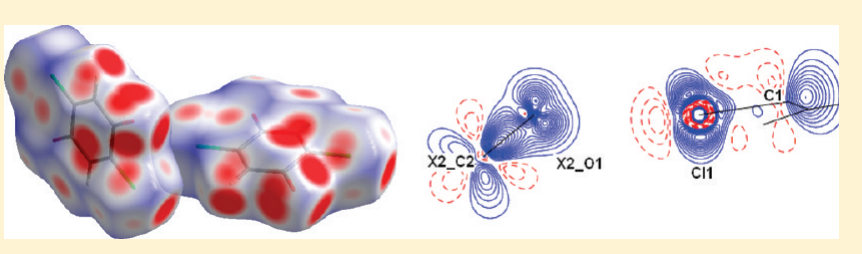
experimental charge density analysis are compared with periodic quantum calculations using B3LYP 6-31G $(d, p)$ level of theory. The topological values at bond critical point, three-dimensional static deformation density features and electrostatic potential isosurfaces unequivocally establish the attractive nature of $\mathrm{C}-\mathrm{Cl} \cdot \mathrm{O}=\mathrm{C}$ halogen bond in crystalline lattice.

\section{INTRODUCTION}

Supramolecular chemistry deals with intermolecular interactions in order to design the structure and function of "supermolecules" by focusing various kinds of strong and weak intermolecular interactions like hydrogen bonds, halogen bonds, $\pi \cdots \pi$ interactions, and van der Waals interactions. The phenomenal role of hydrogen bonds in building a supramolecular assembly in crystal engineering has been vastly studied over the century and is well-documented. ${ }^{2}$ In addition, halogen bonds are short-range weak intermolecular interactions that are analogous to classical hydrogen bonds where polarized halogen atom replaces the hydrogen atom as electron density acceptors in Lewis acid-base pairs. ${ }^{3}$ Initially, these interactions were understood in terms of charge transfer bonds or electron donor-acceptor bonds or transfer of negative charge from Lewis bases like oxygen, nitrogen, etc., to a Lewis acid like polarizable halogen atom. ${ }^{4}$ The polarizable halogens exhibit electrophilic $\left(\delta^{+}\right)$character along the axis of $\mathrm{C}-\mathrm{X}$ bond and nucleophilic $\left(\delta^{-}\right)$character perpendicular to $\mathrm{C}-\mathrm{X}$ bond. ${ }^{5}$ Indeed, electrophiles in general tend to approach halogens at angles of $\cong 90^{\circ}$ and nucleophiles at $\cong 180^{\circ}$. ${ }^{\circ}$ Earlier studies by Hassel identified halogen atoms as recognition sites in self-organization of molecular complexes of $\mathrm{Br}_{2}$ with several other organic compounds by specific $\mathrm{Br} \cdots \mathrm{O}$ interactions. ${ }^{7}$ In recent times, halogen bonds have been exploited to control the crystallization of organic compounds in the design of new functional materials, ${ }^{8}$ supramolecular assemblies in crystal engineering ${ }^{9}$ and in ligand binding and molecular folding in biological systems, ${ }^{10}$ like for example protein kinase complexes with halogenated ligands. Halogen bonds could be either weak or strong based on participating atoms but are highly specific and directional in the geometry and occur very frequently in the crystal structures. ${ }^{8-11}$ It is identified that halogen bonds play a key role in enantiomer separation, ${ }^{12}$ selective binding of small molecules to receptors, ${ }^{13}$ in the formation of supramolecular liquid crystals, ${ }^{14}$ in polymorphic behavior, stability and promotion of crystal growth, ${ }^{11 a, 15}$ and in the formation of molecular conductors. ${ }^{16}$ Moreover, halogen bonds are of significant interest in understanding the mechanism of reactions and chemical reactivity in several organic, metal-organic and biological systems. Charge density analysis based on experimental measurements and periodic theoretical calculations have reached a stage where topological features allow for obtaining net atomic charges and related one electron properties leading to the derivation of features related to chemical bonding directly in both small and large molecules. ${ }^{17}$ The use of 'quantum theory of atoms in molecules' (QTAIM) ${ }^{18}$ approach provides a quantitative link between total electron density and physical properties of a molecule. Charge density studies on halogen

\footnotetext{
Received: January 11, 2011

Revised: February 18, 2011

Published: March 15, 2011
} 
Scheme I. Chemical Structure of 2, 5-Dichloro-1, 4-benzoquinone

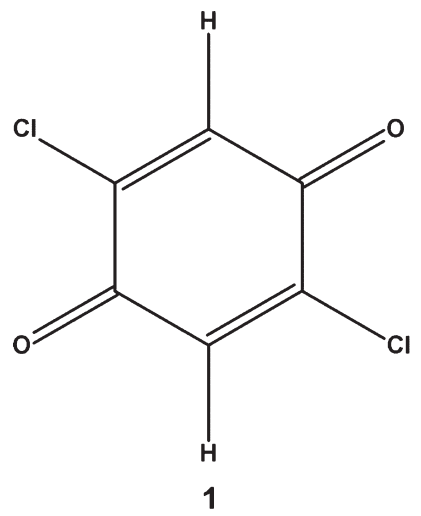

bonding are very sparse. Several groups have carried out theoretical calculations ${ }^{19}$ and crystal structure database studies ${ }^{20}$ to elucidate the nature and propensity of "halogen bonding" contacts. Recently, quantitative charge density analysis based on both theoretical and experimental approaches have been directed toward the understanding of the nature of both homo halogen intermolecular interactions like for example, $\mathrm{Cl} \cdots \mathrm{Cl}^{21 \mathrm{a}, 22}$ and hetero halogen intermolecular interactions like $\mathrm{Cl} \cdots \mathrm{F}^{21 \mathrm{~b}}$ in molecular crystals. Additional experimental charge density studies involving other halogen atoms have been reported to evaluate the nature of halogen bonding in $\mathrm{Br} \cdots \mathrm{N}, \mathrm{I} \cdots \mathrm{O}$ and $\mathrm{I} \cdots \mathrm{N}$ halogen bonds. ${ }^{23,24}$ The concept of "lump-hole interaction" 25 was recently introduced based on theoretical charge density studies to explicitly analyze the nature of halogen bonds.

In this article, we have quantitatively evaluated $\mathrm{C}-\mathrm{Cl} \cdots$ $\mathrm{O}=\mathrm{C}$ halogen bond in 2,5-dichloro-1, 4-benzoquinone (Scheme I) by both experimental and theoretical charge density analysis.

\section{- EXPERIMENTAL AND THEORETICAL SECTION}

Data Collection and Structure Refinement Details. Good quality single crystals of $\mathbf{1}$ were obtained from mixture of chloroform and petroleum ether solvents by slow evaporation at room temperature. Crystals for X-ray diffraction was selected under a polarizing microscope and mounted on a Hampton Research Cryoloop using paratone- $\mathrm{N}$ oil. The crystals were cooled to $90(2) \mathrm{K}$ with a liquid nitrogen stream using an Oxford cryosystem $\left(N_{2}\right.$ open flow cryostat). High resolution X-ray data set up to $(\sin \theta / \lambda)_{\max }=1.08 \AA^{-1}$ with $100 \%$ completeness and good redundancy $(\sim 12)$ was collected on a Bruker AXS Kappa Apex II CCD diffractometer with Mo $\mathrm{K}_{\alpha}$ radiation. The crystal-to-detector distance was fixed to $40 \mathrm{~mm}$ and scan width per frame $(\Delta \omega)$ was $0.5^{\circ}$ during the data collection. The strategy for data collection was obtained by COSMO program of Bruker package suite. ${ }^{26}$ The cell refinement and data reduction were carried out using the SAINTPLUS ${ }^{26}$ and numerical absorption correction was performed by face indexing. The sorting, scaling and merging were carried out using SORTAV. ${ }^{27}$ The structure was solved by direct methods using SHELXS $97^{28}$ and refined in the spherical atom approximation (based on $F^{2}$ ) by SHELXL97 ${ }^{28}$ using the WinGX package suite. ${ }^{29}$ The details of crystal structure and the refinements are listed in Table 1.

Multipole Refinements. The aspherical multipolar refinements based on $F$ were performed using XD2006. ${ }^{30}$ The multipolar atom models used for the descriptions of the total molecular electron density
Table 1. Crystallographic and Experimental Details

\begin{tabular}{|c|c|}
\hline empirical formula & $\mathrm{C}_{6} \mathrm{H}_{2} \mathrm{Cl}_{2} \mathrm{O}_{2}$ \\
\hline $\mathrm{fw}$ & 176.98 \\
\hline cryst syst, space group & monoclinic, $P 2_{1} / c$ \\
\hline$a, b, c(\AA), \beta(\operatorname{deg})$ & $6.0187(3), 5.3451(3), 9.9651(4), 92.604(2)$ \\
\hline$V\left(\AA^{3}\right), Z$ & $320.25(3), 4$ \\
\hline calcd density, $F(000)$ & $1.835,176$ \\
\hline absorption coefficient $\left(\mathrm{mm}^{-1}\right)$ & 0.931 \\
\hline$T(\mathrm{~K}), \lambda(\AA)$ & $90(2), 0.71073$ \\
\hline$(\sin \theta / \lambda)_{\max }\left(\AA^{-1}\right)$ & 1.08 \\
\hline total no. of reflns & 41047 \\
\hline unique no. of reflns & 3380 \\
\hline \multicolumn{2}{|c|}{ completeness (\%), redundancy 99.7, 12.10} \\
\hline$R_{\text {int }}$ & 0.0248 \\
\hline \multicolumn{2}{|c|}{ Spherical Atom Refinement } \\
\hline total no. of reflns $[I>3 \sigma(I)]$ & 3014 \\
\hline$R(F)$ & $0.0211,0.0316$ \\
\hline GoF & 1.900 \\
\hline \multicolumn{2}{|c|}{ Multipole Refinement } \\
\hline refinement based on & $F$ \\
\hline total no. of reflns $[I>3 \sigma(I)]$ & 3014 \\
\hline$R(F), \mathrm{w} R(F)$ & $0.0116,0.0160$ \\
\hline \multicolumn{2}{|l|}{$R(F), \mathrm{w} R(F)$} \\
\hline GoF, $N_{\text {ref }} / N_{\mathrm{v}}$ & $1.003,20.50$ \\
\hline$\Delta \rho_{\min }, \Delta \rho_{\max }\left(\mathrm{e}^{-3}\right)$ & $-0.170,0.176$ \\
\hline CCDC number & 807801 \\
\hline
\end{tabular}

were obtained by the Hansen-Coppens multipole formalism. ${ }^{31}$ Initially, the structure was modeled using the independent atom model (IAM) approximation. The scale factor, atomic positions ( $x y z$ coordinates), and atomic displacement parameters (ADP) were refined with appropriate weighting scheme. The multipolar refinement was carried out with the full-matrix least-squares method using XDLSM module in XD2006. The function minimized was $\sum w\left(\left|F_{0}\right|-K\left|F_{c}\right|\right)^{2}$ for all the reflections with $I>3 \sigma(I)$. Initially, the scale factor was refined against the full resolution of data set. The positional coordinates and the anisotropic thermal displacement parameters of the non-hydrogen atoms were refined against the reflections with $\sin \theta / \lambda>0.8 \AA^{-1}$. The $\mathrm{C}-\mathrm{H}$ bond length was set to $1.083 \AA$ using the neutron diffraction distances available in the literature. ${ }^{32}$ In addition, anharmonicity effects on $\mathrm{Cl}$ atom was modeled with the refinement of the third-order coefficients of a Gram-Charlier expansion using higher order reflections as described in the literature. ${ }^{33}$ It resulted in better residual density features around the $\mathrm{Cl}$ atom. For non-hydrogen atoms, the valence and multipole populations, $\kappa$ and $\kappa^{\prime}$ were allowed to refine in a stepwise manner, until the convergence was reached. The multipole expansion was truncated at the hexadecapole level for the $\mathrm{Cl}$ atom and at the octupole level for $\mathrm{C}$ and $\mathrm{O}$ atoms. Six separate sets of $\kappa$ and $\kappa^{\prime}$ were used to define six different atom types. Initially, only the valence population and the bond directed dipole $\left(d_{z}\right)$ component was refined and $\kappa$ and $\kappa^{\prime}$ were set to the default value of 1.2 for hydrogen atom in the multipolar modeling. Subsequently, the crystal geometry obtained in this stage was used to estimate the ADPs of the hydrogen atom using SHADE2 approach ${ }^{34}$ and obtained values were incorporated in the reconstruction of multipolar modeling along with the quadrupole $\left(q_{3 z^{2}-1}\right)$ component for $\mathrm{H}$ atom.

Theoretical Calculations. Periodic quantum mechanical calculations were performed using the CRYSTAL $06^{35}$ with experimentally observed crystal geometry as input. All the calculations were carried out at the B3LYP 6-31G $(d, p)$ level of theory. ${ }^{36}$ Upon convergence on energy 
$\left(\sim 1 \times 10^{-6}\right)$, the periodic wave function was obtained and theoretical structure factors were derived at the same resolution $\left(1.08 \AA^{-1}\right)$ as observed in the experiment. The multipolar refinements (based on $F$ ) against the theoretical structure factors were carried out using XD2006. The scale factor was fixed to the absolute value (1.0) and thermal displacement parameters were set to zero to consider a static model. Multipolar refinements of theoretical structure factor were performed to the same multipole levels as described for experimental charge density modeling. Additionally, $\kappa$ and $\kappa^{\prime}$ of $\mathrm{H}$ atom were allowed to refine during the multipolar refinements. Further, the experimental multipole model was reconstructed by fixing the values of $\kappa$ and $\kappa^{\prime}$ of $\mathrm{H}$ atom obtained from the theoretical multipole modeling to compare the results from both experimental and theoretical modeling.

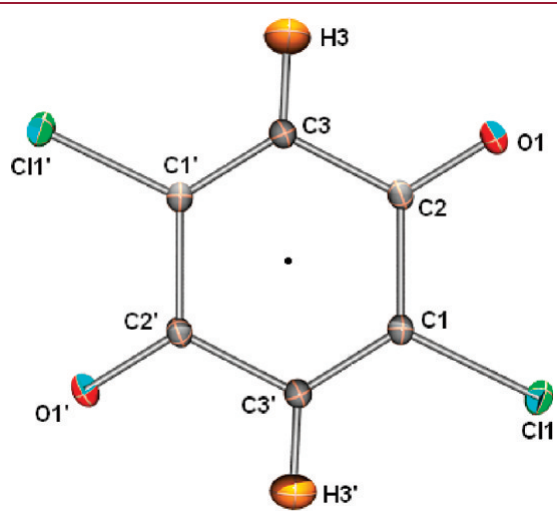

Figure 1. ORTEP of 1 with $50 \%$ ellipsoid probability at $90 \mathrm{~K}$ and $\mathrm{H}$ atoms are shown with anisotropic displacement parameters obtained from SHADE $2^{34}$ analysis. The dot represents inversion symmetry of the molecule.

\section{RESULTS AND DISCUSSION}

Crystal Structure. The crystal structure of $\mathbf{1}$ at room temperature was earlier reported by Rees. ${ }^{37}$ In the present study, we have freshly grown the crystals of compound $\mathbf{1}$ and redetermined its structure using high resolution data at 90K. An ORTEP of the molecule drawn at $50 \%$ probability is shown in Figure 1. Molecules of 1 assemble around the $2_{1}$ screw axis to form a helical motif along a crystallographic $b$ axis (Figure 2a). The adjacent molecules along the helix are linked by $\mathrm{C}-\mathrm{Cl} \cdot \mathrm{O}=\mathrm{C}$ halogen bonds ( $\mathrm{Cl}$ atom as Lewis acid and carbonyl oxygen atom, $\mathrm{C}=\mathrm{O}$ as Lewis base) with $\mathrm{Cl} \cdots \mathrm{O}$ distance of 3.0562(3) $\AA$ and the angle $\mathrm{C}-\mathrm{Cl} \cdots \mathrm{O}$ of $164.7^{\circ}$. The neighboring helices are packed compactly diagonal to the ac-plane and are linked via weak $\mathrm{C}-\mathrm{H} \cdots \mathrm{O}, \mathrm{C}-\mathrm{H} \cdots \mathrm{Cl}, \mathrm{C}=\mathrm{O} \cdots \pi$, and dipolar $\mathrm{C}-$ $\mathrm{Cl} \cdot \mathrm{C}-\mathrm{Cl}$ contacts (Figure $2 \mathrm{~b}, \mathrm{c}$ ). Further, weak $\mathrm{C}-\mathrm{Cl} \cdots$ $\mathrm{Cl}-\mathrm{C}$ interactions (distances of 3.721(3) $\AA$ and 3.765(3) $\AA$ ), $\mathrm{C}-\mathrm{H} \cdots \mathrm{O}\left(\mathrm{H} \cdots \mathrm{O}=2.440(2) \AA\right.$ and $\left.\angle \mathrm{C}-\mathrm{H} \cdots \mathrm{O}=148^{\circ}\right)$ and $\mathrm{C}-\mathrm{H} \cdots \mathrm{Cl}(\mathrm{H} \cdots \mathrm{Cl}=2.944(2) \AA$ and $\angle \mathrm{C}-\mathrm{H} \cdot \cdots \mathrm{O}=$ $114^{\circ}$ ) interactions are generated in the crystalline lattice (Figure 2c). It is of interest to note that the packing of molecules in crystal structure is entirely governed by weak but highly directional interactions, the dominant one being the $\mathrm{C}-\mathrm{Cl} \cdot \mathrm{O}=\mathrm{C}$ halogen bond with the others acting as surrogate interactions.

Hirshfeld Surface Analysis. Further, the intermolecular contacts in the crystal structure of 1 are quantified via Hirshfeld surface analysis ${ }^{38}$ using the CrystalExplorer. ${ }^{39}$ Hirshfeld surfaces are a novel tool for visualization and understanding of intermolecular interactions. ${ }^{40}$ In the present study, the contacts involving $\mathrm{Cl}$ atom, the $\mathrm{C}-\mathrm{H} \cdots \mathrm{O}$ and $\mathrm{C} \cdots \mathrm{O}$ contacts are evaluated. The percentage of contributions to the Hirshfeld surface areas for these and "other" $(\mathrm{O} \cdots \mathrm{O}, \mathrm{C} \cdots \mathrm{H}$, and $\mathrm{H} \cdot \cdot \mathrm{H})$ intermolecular contacts are shown in Figure 3. The (a)

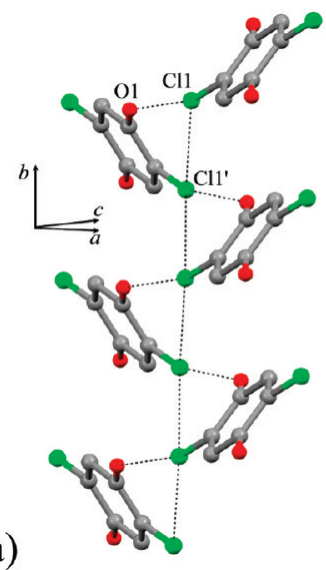

(b)

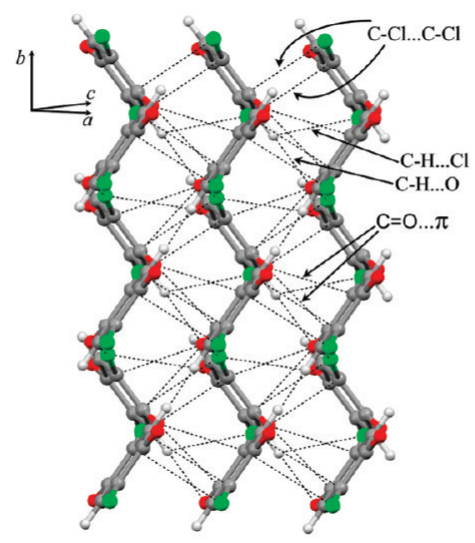

(c)

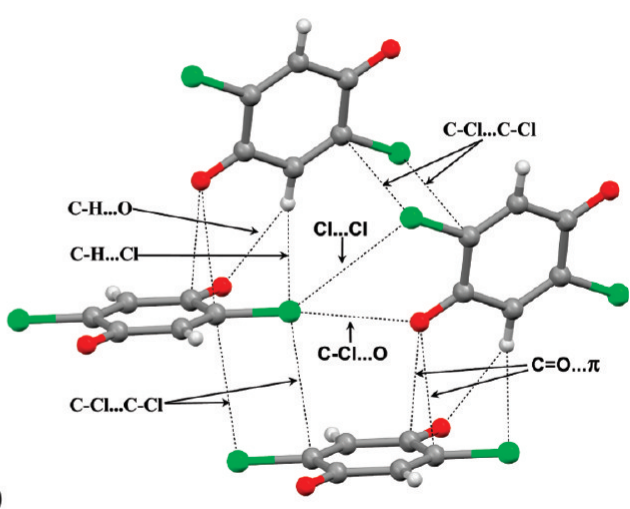

Figure 2. (a) Helical assembly of molecules of 1 across crystallographic $2_{1}$ screw axis connected through the halogen bonding interaction; (b) interlinking of neighboring helices via other intermolecular contacts; (c) a depiction of the closely related molecules linked via weak intermolecular interactions.

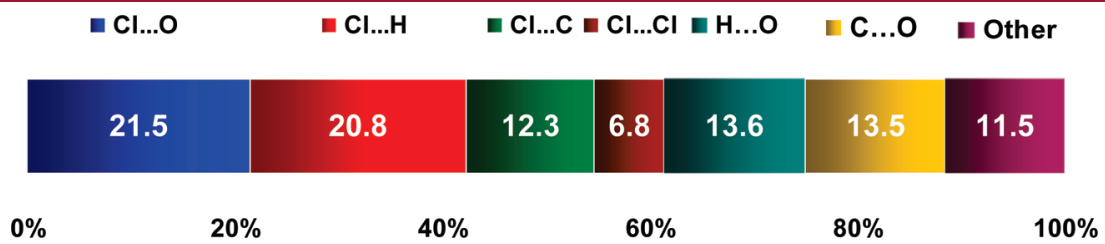

Figure 3. Percentage contributions to the Hirshfeld surface areas for various intermolecular contacts. 
chart in Figure 3 indicates that the $\mathrm{C}-\mathrm{Cl} \cdots \mathrm{O}=\mathrm{C}$ halogen bonds are indeed the dominating one $(21.5 \%)$, whereas only $\sim 7 \%$ contribution comes from the weak $\mathrm{Cl} \cdots \mathrm{Cl}$ contacts. The $\mathrm{H} \cdots \mathrm{O}$ and $\mathrm{C} \cdots \mathrm{O}$ contacts both contributes $\sim 13.5 \%$ to the Hirshfeld surface areas. However, it is noteworthy that these percentage contributions do not discriminate between the close and distant contacts. The major contacts $\mathrm{C}-\mathrm{Cl} \cdots \mathrm{O}=\mathrm{C}$ halogen bonds, $\mathrm{C}-\mathrm{Cl} \cdot \mathrm{H}-\mathrm{C}, \mathrm{C}-\mathrm{H} \cdot \mathrm{O}=\mathrm{C}$ and $\mathrm{C}=\mathrm{O} \cdots$ $\mathrm{C}$ along with the $\mathrm{Cl} \cdots \mathrm{Cl}$ contacts are highlighted by conventional mapping of $\mathrm{d}_{\text {norm }}$ on molecular Hirshfeld surfaces (Figure 4). The dark red spots on the right are due to the $\mathrm{C}-\mathrm{Cl} \cdots \mathrm{O}=\mathrm{C}$ halogen bonds while that on the top are from $\mathrm{C}-\mathrm{H} \cdots \mathrm{Cl}$ contacts and on the bottom-left are due to the $\mathrm{C}-\mathrm{H} \cdots \mathrm{O}=\mathrm{C}$ (from left) and $\mathrm{C}=\mathrm{O} \cdots \mathrm{C}$ (facing the surface) contacts. The faded red spot on the right and in between the two $\mathrm{C}-\mathrm{Cl} \cdot \mathrm{O}=\mathrm{C}$ halogen bonds representing the weak $\mathrm{Cl} \cdots \mathrm{Cl}$ contact.

Multipolar Modeling and Deformation Electron Densities. Initially, the correctness of multipolar modeling was accessed by the Hirshfeld rigid bond test ${ }^{41}$ for all the covalent bonds involving non hydrogen atoms. The largest differences of mean-square displacement amplitudes (DMSDA) is found to be $4(2) \times 10^{-4} \AA^{2}$ for $\mathrm{Cl}(1)-\mathrm{C}(1)$ bond. In addition, the minimum

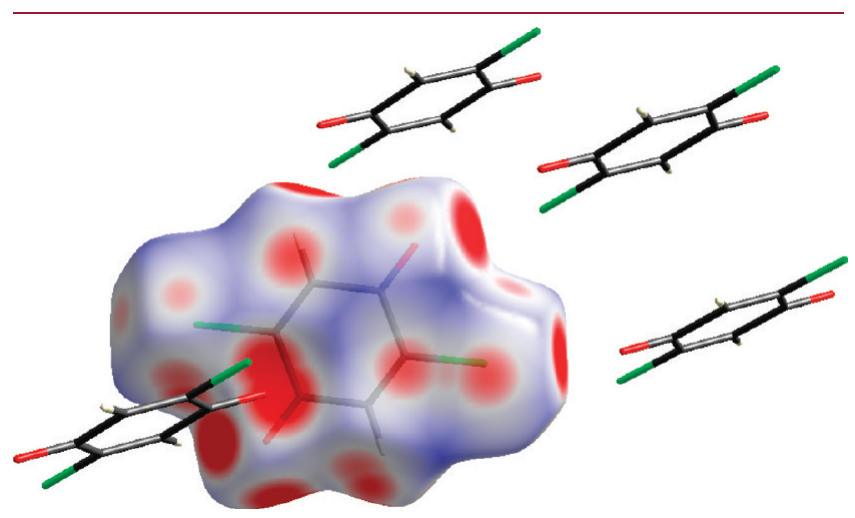

Figure 4. $d_{\text {norm }}$ mapped on Hirshfeld Surfaces for visualizing the $\mathrm{C}-\mathrm{Cl} \cdots \mathrm{O}=\mathrm{C}$ halogen bond, $\mathrm{C}-\mathrm{Cl} \cdots \mathrm{H}-\mathrm{C}, \mathrm{C}-\mathrm{H} \cdots \mathrm{O}=\mathrm{C}$ and $\mathrm{C}=\mathrm{O} \cdots \mathrm{C}$ contacts along with the weak $\mathrm{Cl} \cdots \mathrm{Cl}$ contact. and maximum densities over the asymmetric unit are -0.170 and $+0.176 \mathrm{e}^{-3}$ in experimental modeling whereas they are -0.130 and $+0.047 \mathrm{e}^{-3}$ in theoretical modeling. These residual density values are comparable to the values reported earlier in the charge density analysis of organic compounds containing $\mathrm{Cl}$ atoms. $^{21,22}$ The static deformation density (Figure 5) and Laplacian (Figure 6) maps obtained from both experimental and theoretical multipole refinements are in agreement and display all the expected subtle bonding features like 'lone pair' on carbonyl oxygen. Aspherical nature of the charge density distribution around the $\mathrm{Cl}$ atom is observed in the static deformation density maps due to the polar flattening effects (Figure 5). Indeed these features are better depicted in the $3 \mathrm{D}$ static deformation density maps for $\mathrm{C}-\mathrm{Cl} \cdots \mathrm{O}=\mathrm{C}$ halogen bond in intermolecular region (Figure $7 \mathrm{c}$ and $7 \mathrm{~d}$ ). The corresponding Laplacian maps of $\mathrm{C}-\mathrm{Cl} \cdot \mathrm{O}=\mathrm{C}$ halogen bond further support this observation along with $(3,-1)$ bond critical point $(\mathrm{BCP})$ (Figure 8).

The topological values $\left(R_{\mathrm{ij}}, \rho\left(r_{\mathrm{b}}\right), \nabla^{2} \rho\left(r_{\mathrm{b}}\right)\right.$, and $\left.\varepsilon\right)$ of all covalent bonds of $\mathbf{1}$ at the BCP obtained from both experiment and theoretical analyses are listed in Table S1 (see the Supporting Information). The good agreement between the values derived from experimental and theoretical approaches demonstrates that both the methodologies are consistent in deriving the topological properties at BCP. As we discussed earlier, the crystal structure of $\mathbf{1}$ is stabilized by additional surrogate weak interactions $[\mathrm{Cl} \cdots \mathrm{H}, \mathrm{Cl} \cdots \mathrm{C}, \mathrm{Cl} \cdots \mathrm{Cl}, \mathrm{H} \cdots \mathrm{O}$ and "other" $(\mathrm{O} \cdots \mathrm{C}$, $\mathrm{O} \cdot \cdots \mathrm{O}, \mathrm{C} \cdot \mathrm{H}$ and $\mathrm{H} \cdots \mathrm{H}$ ) intermolecular contacts]. The topological properties of all these additional interactions are listed in Table 2.

Three-Dimensional Static Deformation Density and Topological Features of $\mathrm{C}-\mathrm{Cl} \cdots \mathrm{O}=\mathrm{C}$ Halogen Bond. $2 \mathrm{D}$ and $3 \mathrm{D}$ static deformation density maps plotted in $\mathrm{C}-\mathrm{Cl} \cdot \mathrm{O}=\mathrm{C}$ intermolecular space clearly show the apherical distribution of electron density around the $\mathrm{Cl}$ atom (Figure 7). An electrophilic $\left(\delta^{+}\right)$region on the $\mathrm{Cl}$ atom along the $\mathrm{C}-\mathrm{Cl}$ bond axis is interacting with nucleophilic $\left(\delta^{-}\right)$carbonyl oxygen. Aspherical nature of electron density around the $\mathrm{Cl}$ atom is also depicted in Laplacian maps of $\mathrm{C}-\mathrm{Cl} \cdots \mathrm{O}=\mathrm{C}$ interaction region (Figure 8). The positive electron density region is pointing toward the lone pair of oxygen atom in intermolecular space. These deformation (a)

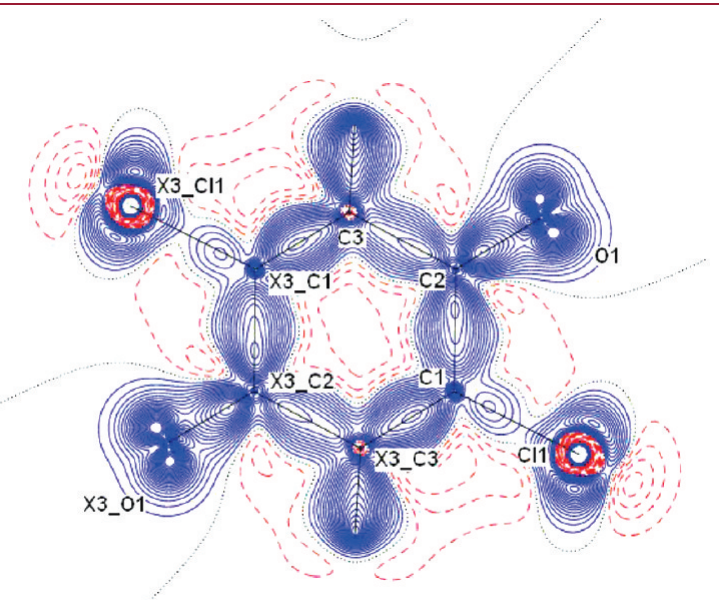

(b)

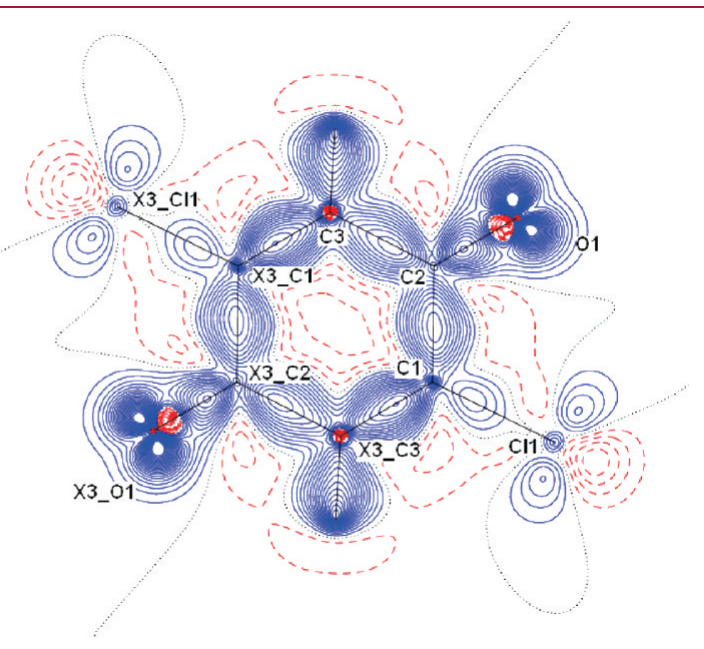

Figure 5. Static deformation density maps from (a) experimental and (b) theoretical charge density modeling for $\mathbf{1}$. The positive (solids blue lines) and negative (broken red lines) contours are drawn at intervals of \pm 0.05 e $\AA^{-3}$ and zero contours are shown as the black dotted line. X3 indicate the symmetry code $-x+2,-y+1,-z$. 
(a)

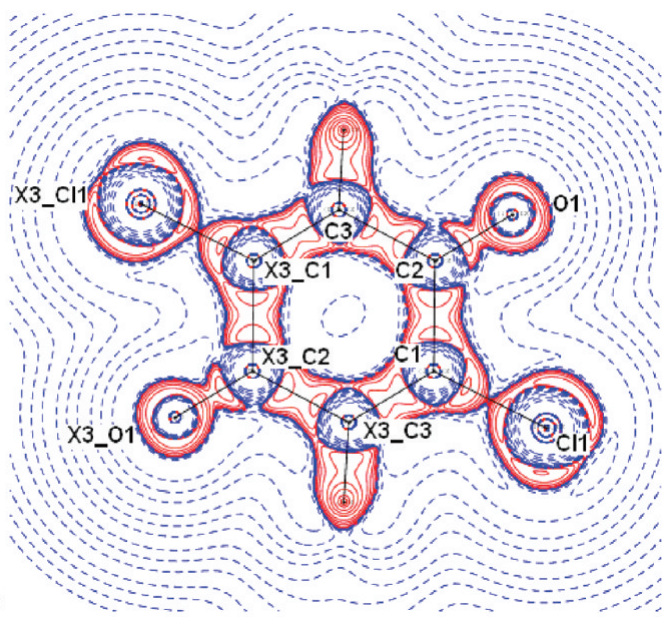

(b)

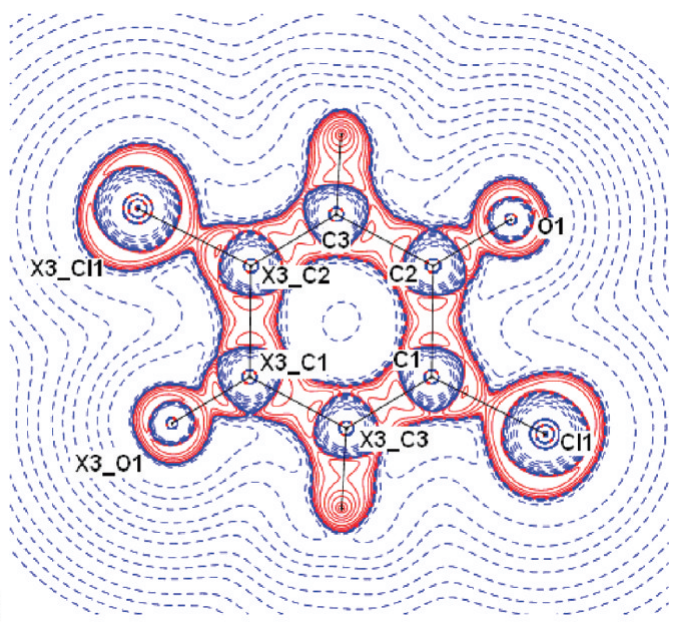

Figure 6. Laplacian maps for $\mathbf{1}$ from (a) experimental and (b) theoretical charge density modeling. Contours are drawn at logarithmic intervals in $\nabla^{2} \rho\left(r_{\mathrm{b}}\right)$, e $\AA^{-5}$. Blue lines indicate positive contours and red lines indicate negative contours. X3 indicate the symmetry code $-x+2,-y+1,-z$.

(a)

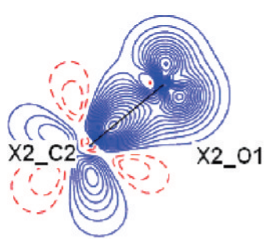

(c)

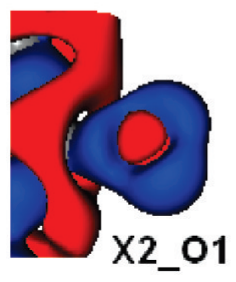

(b)
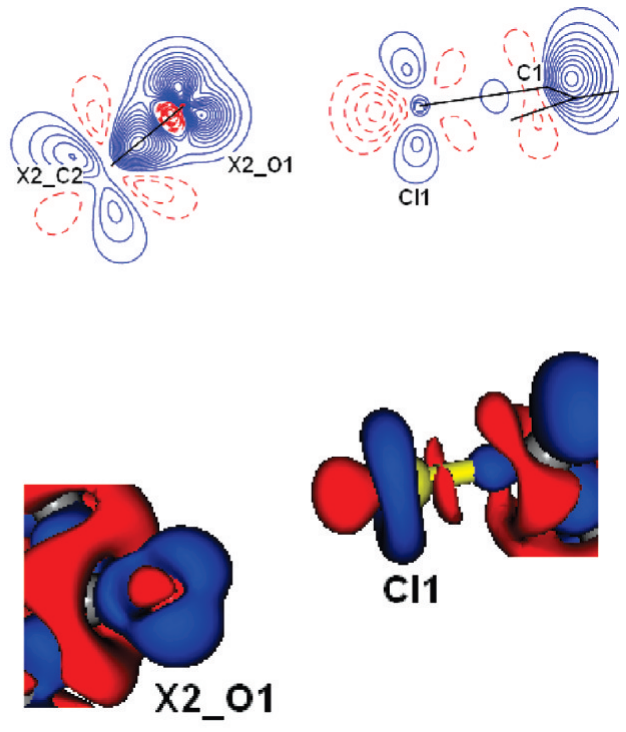

(d)

Figure 7. $2 \mathrm{D}$ static deformation density maps for $\mathrm{C}-\mathrm{Cl} \cdots \mathrm{O}=\mathrm{C}$ halogen bond from $(\mathrm{a})$ experimental and (b) theoretical charge density modeling for 1. The positive (solids blue lines) and negative (broken red lines) contours are drawn at intervals of $\pm 0.05 \mathrm{e}^{-3}$. The corresponding $3 \mathrm{D}$ plots from both experiment and theory were given in (c) and (d) respectively. X2 indicate the symmetry code $-x+1, y+1 / 2,-z+1 / 2$.
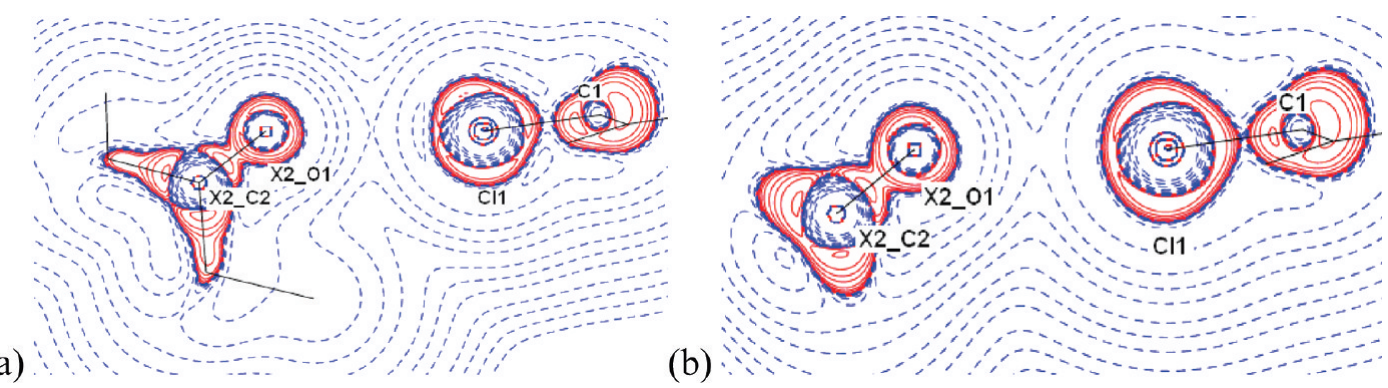

(b)

Figure 8. Laplacian maps for $\mathrm{C}-\mathrm{Cl} \cdots \mathrm{O}=\mathrm{C}$ halogen bond from (a) experimental and (b) theoretical charge density modeling for 1. Contours are drawn at logarithmic intervals in $\nabla^{2} \rho\left(r_{\mathrm{b}}\right), \mathrm{e} \AA^{-5}$. Blue lines indicate positive contours and red lines indicate negative contours. X2 indicate the symmetry code $-x+1, y+1 / 2,-z+1 / 2$.

density features were observed in $\mathrm{Cl} \cdots \mathrm{Cl}$ intermolecular interactions. ${ }^{21 a, 22}$ In addition, recently halogen bonding is described as an interaction between a region of charge depletion (CD) referred to as a "hole" on the halogen atom and a region of charge 
Table 2. Topological Features of All Interactions in $1 .^{a}$

\begin{tabular}{|c|c|c|c|c|c|c|c|c|c|}
\hline interactions & $R_{i j}(\AA)$ & $\begin{array}{c}\rho\left(\mathrm{r}_{b}\right) \\
\left(\mathrm{e} \AA^{-3}\right)\end{array}$ & $\begin{array}{l}\nabla^{2} \rho\left(\mathrm{r}_{b}\right) \\
\left(\mathrm{e} \AA^{-5}\right)\end{array}$ & $d_{1}(\AA)$ & $d_{2}(\AA)$ & $\begin{array}{c}G\left(\mathrm{r}_{\mathrm{b}}\right) \\
\left(\mathrm{kJ} \mathrm{mol}^{-1} \mathrm{bohr}^{-3}\right)\end{array}$ & $\begin{array}{c}V\left(\mathrm{r}_{\mathrm{b}}\right) \\
\left(\mathrm{kJ} \mathrm{mol}^{-1} \mathrm{bohr}^{-3}\right)\end{array}$ & $\begin{array}{c}E\left(\mathrm{r}_{\mathrm{b}}\right) \\
\left(\mathrm{kJ} \mathrm{mol}^{-1} \mathrm{bohr}^{-3}\right)\end{array}$ & $\begin{array}{c}\left|V\left(r_{\mathrm{b}}\right)\right| / \\
G\left(r_{\mathrm{b}}\right)\end{array}$ \\
\hline $\mathrm{Cl} \cdot \cdots \mathrm{O} 1$ & $3.0562(3)$ & $0.054(1)$ & $0.795(1)$ & 1.6119 & 1.4444 & 16.2 & -10.8 & 5.4 & 0.67 \\
\hline$-x+1, y+1 / 2,-z+1 / 2$ & 3.0563 & $0.059(2)$ & $0.848(0)$ & 1.6283 & 1.4281 & 17.5 & -11.8 & 5.7 & 0.67 \\
\hline $\mathrm{O} 1 \cdots \mathrm{H} 3$ & $2.4398(2)$ & $0.062(5)$ & $0.527(3)$ & 1.4454 & 0.9944 & 11.8 & -9.3 & 2.5 & 0.78 \\
\hline$-x+2, y+1 / 2,-z+1 / 2$ & 2.4398 & $0.053(3)$ & $0.588(2)$ & 1.4737 & 0.9661 & 12.4 & -8.7 & 3.7 & 0.70 \\
\hline $\mathrm{Cl} 1 \cdots \mathrm{Cl} 1$ & $3.7212(1)$ & $0.023(3)$ & $0.312(1)$ & 1.8508 & 1.8704 & 6.1 & -3.6 & 2.5 & 0.58 \\
\hline$-x+1, y-1 / 2,-z+1 / 2$ & 3.7213 & $0.031(3)$ & $0.380(2)$ & 1.8819 & 1.8395 & 7.6 & -4.9 & 2.7 & 0.64 \\
\hline $\mathrm{Cl} 1 \cdots \mathrm{Cl} 1$ & $3.7655(1)$ & $0.029(4)$ & $0.405(2)$ & 1.8742 & 1.8913 & 8.0 & -4.7 & 3.3 & 0.59 \\
\hline$-x+1, y+1,-z$ & 3.7655 & $0.035(2)$ & $0.411(1)$ & 1.8827 & 1.8827 & 8.3 & -5.6 & 2.7 & 0.67 \\
\hline $\mathrm{Cl} \cdots \mathrm{H} 3$ & $2.9443(2)$ & $0.036(1)$ & $0.592(1)$ & 1.7952 & 1.1491 & 11.7 & -7.0 & 4.7 & 0.60 \\
\hline$-x+2, y+1 / 2,-z+1 / 2$ & 2.9443 & $0.037(4)$ & $0.609(1)$ & 1.8054 & 1.1389 & 12.0 & -7.6 & 4.4 & 0.63 \\
\hline $\mathrm{O} 1 \cdots \mathrm{C} 1$ & $3.0982(3)$ & $0.035(2)$ & $0.535(1)$ & 1.5391 & 1.5561 & 10.6 & -6.4 & 4.2 & 0.61 \\
\hline$-x+2, y-1 / 2,-z+1 / 2$ & 3.0982 & $0.036(1)$ & $0.524(0)$ & 1.5446 & 1.5535 & 10.4 & -6.7 & 3.7 & 0.65 \\
\hline $\mathrm{O} 1 \cdots \mathrm{C} 2$ & $3.0004(3)$ & $0.043(2)$ & $0.564(1)$ & 1.5122 & 1.4883 & 11.5 & -7.7 & 3.8 & 0.67 \\
\hline$-x+1, y-1 / 2,-z+1 / 2$ & 3.0004 & $0.035(1)$ & $0.570(0)$ & 1.5484 & 1.4558 & 11.2 & -6.5 & 4.7 & 0.58 \\
\hline
\end{tabular}

${ }^{a} d_{1}$ and $d_{2}$ are the distances from the CP to the first atom (A) and second atom (B), respectively. Interaction length $R_{i j}=\left(d_{1}+d_{2}\right)$. The values from periodic calculations using B3LYP/6-31G $(d, p)$ method are given in italics.

concentration (CC) referred to as a "lump" on participating atom. $^{25}$

A similar feature is observed in 3D static deformation density plots of $\mathrm{C}-\mathrm{Cl} \cdot \mathrm{O}=\mathrm{C}$ intermolecular space. The "hole" corresponding to the charge depletion (CD) on the $\mathrm{Cl}$ atom (shown in red) faces the "lump" on carbonyl oxygen atom (shown in blue) (Figure $7 \mathrm{c}, \mathrm{d}$ ). This feature of $\mathrm{Cl}$ atom is analogous to $\mathrm{H}$ atoms in routine classical hydrogen bonds. Hence $\mathrm{C}-\mathrm{Cl} \cdots$ $\mathrm{O}=\mathrm{C}$ halogen bond is $\delta^{+} \cdots \delta^{-}$type of interaction and the nature of interaction is attractive. ${ }^{21,22}$

The topological analysis of the total electron density $\rho\left(r_{\mathrm{b}}\right)$ and other $\mathrm{BCP}$ properties were performed for $\mathrm{C}-\mathrm{Cl} \cdot \mathrm{O}=\mathrm{C}$ halogen bond using XDPROP module. ${ }^{30}$ The $\rho\left(r_{\mathrm{b}}\right)$ and $\nabla^{2} \rho\left(r_{\mathrm{b}}\right)$ values are $0.054(0.059)$ e $\AA^{-3}$ and $0.795(0.848)$ e $\AA^{-5}$, respectively (Table 2 ) and these values show similar trend with the reported values from theoretical charge density analysis in the literature. ${ }^{17}$ The Laplacian value is a measure of the local curvature of $\rho\left(r_{\mathrm{b}}\right)$ and indicates whether the electron density is locally concentrated $\left(\nabla^{2} \rho\left(r_{\mathrm{b}}\right)<0\right)$ or depleted $\left(\nabla^{2} \rho\left(r_{\mathrm{b}}\right)>0\right)$ at given point in space. In the case of halogen bond, the value of $\rho\left(\mathrm{r}_{\mathrm{b}}\right)$ is small and $\left(\nabla^{2} \rho\left(r_{\mathrm{b}}\right)>0 .{ }^{18}\right.$ This quantifies $\mathrm{C}-\mathrm{Cl} \cdots$ $\mathrm{O}=\mathrm{C}$ interaction as closed shell interactions. Further, values of the kinetic energy density $G\left(r_{\mathrm{b}}\right)$ and the potential energy density $V\left(r_{\mathrm{b}}\right)$ of $\mathrm{C}-\mathrm{Cl} \cdots \mathrm{O}=\mathrm{C}$ bond at $\mathrm{BCP}$ are calculated using the Abramov's expression ${ }^{42}$ for closed shell interactions. The corresponding values of $G\left(r_{\mathrm{b}}\right)$ and $V\left(r_{\mathrm{b}}\right)$ for $\mathrm{C}-\mathrm{Cl} \cdots \mathrm{O}=\mathrm{C}$ halogen bond are $16.2(17.5) \mathrm{kJ} \mathrm{mol}^{-1} \mathrm{bohr}^{-3}$ and $-10.8(-11.8) \mathrm{kJ}$ $\mathrm{mol}^{-1}$ bohr $^{-3}$ respectively (Table 2 ). The total energy density, $E\left(r_{\mathrm{b}}\right)$ sum of kinetic and potential energy densities) at BCP is $5.4(5.7) \mathrm{kJ} \mathrm{mol}^{-1} \mathrm{bohr}^{-3}$. The kinetic energy density dominates both the local electronic energy and the local virial relationship. This situation is observed in the case of closed shell interactions. $^{42}$

Further, the interactions can be classified as closed shell interaction if the values of $\left|V\left(r_{\mathrm{b}}\right)\right| / G\left(r_{\mathrm{b}}\right)<1 .^{42 \mathrm{~b}, \mathrm{c}}$ The ratio of $\left|V\left(r_{\mathrm{b}}\right)\right| / G\left(r_{\mathrm{b}}\right)$ for $\mathrm{C}-\mathrm{Cl} \cdots \mathrm{O}=\mathrm{C}$ bond is found to be $0.67(0.67)$. In addition, the total interaction energy $\left(E_{\text {int }}\right)$ for $\mathrm{C}-\mathrm{Cl} \cdots$ $\mathrm{O}=\mathrm{C}$ halogen bond is calculated as pairwise interaction energy between neighboring molecules involving these two participating (a)

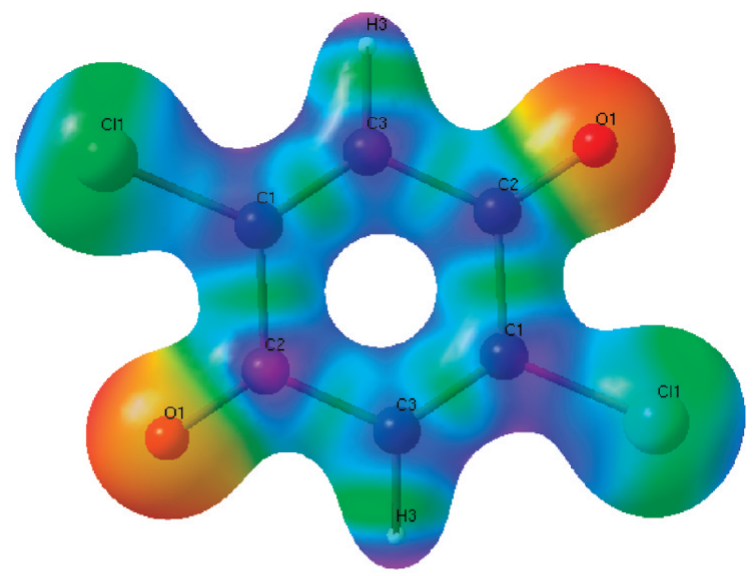

(b)

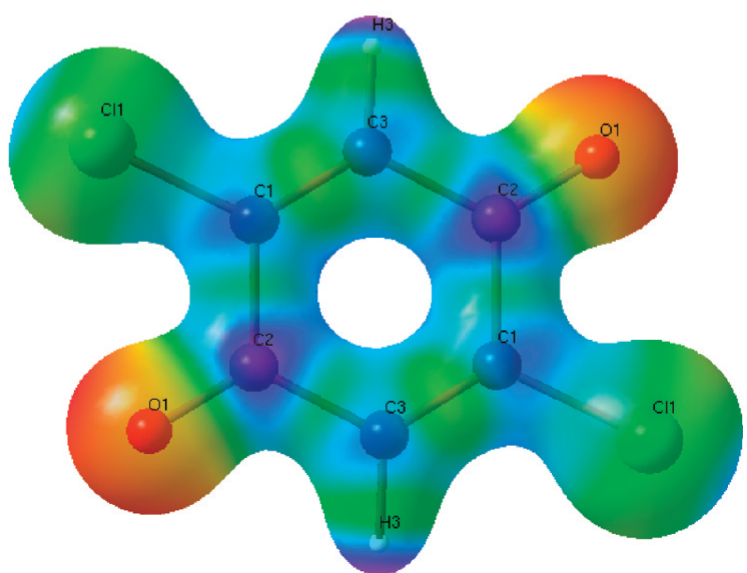

Figure 9. Electrostatic potential isosurface maps from (a) experimental and (b) theoretical charge density modeling drawn at isosurface value of $\pm 0.5 \mathrm{e} \AA^{-3}$. Blue and red colors represent electropositive and electronegative regions, respectively.

atoms as discussed in the literature. ${ }^{43}$ These calculations include dispersion, exchange-repulsion and electrostatic terms. Williams 
and Cox's potential ${ }^{44}$ is used for calculation of dispersion and exchange-repulsion terms. $E_{\text {int }}$ value for $\mathrm{C}-\mathrm{Cl} \cdots \mathrm{O}=\mathrm{C}$ halogen bond is found to be $-5.95 \mathrm{~kJ} \mathrm{~mol}^{-1}$ and $-4.92 \mathrm{~kJ} \mathrm{~mol}^{-1}$ from both experiment and theoretical calculations, respectively. It is interesting to note that the net atomic charges calculated on $\mathrm{Cl}$ and $\mathrm{O}$ atoms in $\mathrm{C}-\mathrm{Cl} \cdots \mathrm{O}=\mathrm{C}$ bond from both experiment and theoretical multipolar models are $+0.14 e(+0.02 e)$ and $-0.27 e(-0.14 e)$ respectively. This strongly supports our observation on $\mathrm{C}-\mathrm{Cl} \cdots$ $\mathrm{O}=\mathrm{C}$ halogen bond as $\delta^{+} \cdots \delta^{-}$type of interactions and attractive nature of halogen bonds (see the Supporting Information, Table S2).

In addition, the significant differences observed in the features of the deformation density maps around the $\mathrm{Cl}$ atom in both experimental and theoretical studies needs to be addressed (Figures $7 \mathrm{a}$ and $7 \mathrm{~b}$ ). This has been discussed in detail in our earlier studies on short $\mathrm{Cl} \cdots \mathrm{Cl}$ intermolecular interactions. ${ }^{21 a}$ Such differences have been attributed to be due to the inadequacy of the theoretical basis set associated with the halogen atoms. ${ }^{45}$ The use of higher level basis sets could help in obtaining theoretical structure factors with higher accuracy. However, it is to be mentioned that with the present treatment, the nature of electron distribution around the $\mathrm{Cl}$ atom is almost comparable in both experimental and theoretical calculations. It is further supported by comparable topological values at BCP (Table 2). Hence, the decisive conclusion on the nature of halogen bonding in molecular crystals can be established by present charge density studies.

Electrostatic Potential Isosurfaces. The electrostatic potential is obtained on an isolated molecule extracted from the crystal lattice using the XD2006. ${ }^{30}$ The analysis of electrostatic potential (ESP) on the molecular surfaces predict the effect of crystalline environment to generate noncovalent interactions and the distribution of electron density in the molecule is clearly depicted using the package MOLISO. ${ }^{46}$ Electropositive, electronegative and neutral isosurface regions are indicated by blue, red and green colors respectively (Figure 9). The electrostatic potential around the $\mathrm{Cl}$ atom is depicting the polar flattening effects as the blue surface is pointing along the $\mathrm{C}-\mathrm{Cl}$ covalent bond, whereas the green surface (less negative than red surfaces) is perpendicular $\mathrm{C}-\mathrm{Cl}$ bond. The hydrogen atoms are positively polarized and oxygen atoms are negatively polarized as indicated by blue and red surfaces respectively. These features support the attractive and directional nature of halogen bonds as the electrophilic $\left(\delta^{+}\right)$region of the $\mathrm{Cl}$ atom points toward the nucleophilic $\left(\delta^{-}\right)$ carbonyl oxygen. It may be pointed out that the ESP isosurfaces from theoretical charge density calculations (Figure 9b) are also in one-to-one correspondence with experimental values. Our results were well supported by earlier theoretical works in the literature. ${ }^{47,48}$ The presence of positive electrostatic potential regions on the outermost portion of covalently bonded halogen atoms was previously observed in high level theoretical calculations of electrostatic potentials in halogen substituted compounds by Politzer ${ }^{47}$ and the phenomena was explained in terms $\sigma$-hole formation in halogen atom along the $\mathrm{C}-\mathrm{X}$ bond.

\section{- CONCLUSION}

$\mathrm{C}-\mathrm{Cl} \cdots \mathrm{O}=\mathrm{C}$ bond is quantitatively characterized by charge density studies on halogen bond using both high resolution experiment and periodic quantum calculations. Hirshfeld partitioning scheme is used to visualize the $\mathrm{C}-\mathrm{Cl} \cdots \mathrm{O}=\mathrm{C}$ halogen bond while QTAIM partitioning scheme is employed for its characterization. The nature of halogen bond is attractive as participating atoms have $\delta^{+} \cdots \delta^{-}$type of interactions. Hence halogen bonds are highly directional in generating as well as stabilizing the supramolecular architecture in the crystal engineering. The present work quantitatively evaluates the topological features associated with the halogen bonds as weak interactions, which are analogous to classical hydrogen bonds.

\section{ASSOCIATED CONTENT}

(5) Supporting Information. Crystallographic information file (CIF); tables of topological features associated with all covalent bonds and net atomic charges of all atoms for $\mathbf{1}$ (PDF).This material is available free of charge via the Internet at http://pubs.acs.org.

\section{AUTHOR INFORMATION}

\section{Corresponding Author}

*E-mail: ssctng@sscu.iisc.ernet.in. Telephone: +91-80-22962796. Fax: $+91-80-23601310$.

\section{ACKNOWLEDGMENT}

V.R.H. thanks IISc for research fellowships. The authors thank IISc for X-ray diffraction facility. TNGR thanks Department of Science and technology, New Delhi, for the award of J. C. Bose fellowship. P.M. thanks the European Commission for the award of Marie Curie International Incoming Fellowship within the 7th European Community Framework Programme.

\section{REFERENCES}

(1) (a) Lehn, J.-M. Supramolecular Chemistry: Concepts and Perspectives; Wiley-VCH: Weinheim, Germany, 1995. (b) Desiraju, G. R. Angew. Chem., Int. Ed. 1995, 34, 2311-2327. (c) Steiner, T. Angew. Chem. Int. Ed. 2002, 41, 48-76. (d) Desiraju, G. R. Angew. Chem., Int. Ed. 2007, 46, 8342-8356. (e) Nangia, A. J. Chem. Sci. 2010, 122, 295-310.

(2) (a) Hamilton, W. C.; Ibers, J. A. Hydrogen Bonding in Solids; Benjamin: New York, 1968. (b) Desiraju, G. R. Crystal Engineering: The Design of Organic Solids; Elsevier: Amsterdam, 1989. (c) Jeffrey, G. A.; Saenger, W. Hydrogen Bonding in Biological Structures; Springer: Berlin, 1991. (d) Jeffrey, G. A. An Introduction to Hydrogen Bonding; Oxford University Press: Oxford, U.K., 1997. (e) Scheiner, S. Hydrogen Bonding. A Theoretical Perspective; Oxford University Press: Oxford, U.K., 1997. (f) Desiraju, G. R.; Steiner, T. The Weak Hydrogen Bond in Structural Chemistry and Biology; Oxford University Press: Oxford, U.K., 1999. (g) Desiraju, G. R. Angew. Chem. Int. Ed. 2010, 49, 2-10.

(3) (a) Legon, A. C. Angew. Chem., Int. Ed. 1999, 38, 2686-2714.(b) Halogen Bonding: Fundamentals and Applications; Metrangolo, P., Resnati, G., Eds.; Springer: Berlin, 2008. (c) Legon, A. C. Phys. Chem. Chem. Phys. 2010, 12, 7736-7747.

(4) Legon, A. C. In Halogen Bonding: Fundamentals and Applications; Metrangolo, P., Resnati, G., Eds.; Springer: Berlin, 2008; pp 17-64.

(5) Bosch, E.; Barnes, C. L. Cryst. Growth Des. 2002, 2, 299-302.

(6) (a) Rosenfield, R. E.; Parthasarathy, R.; Dunitz, J. D. J. Am. Chem. Soc. 1977, 99, 4860-4862. (b) Row, T. N. G.; Parthasarathy, R. J. Am. Chem. Soc. 1981, 103, 477-479. (c) Ramasubbu, N.; Parthasarathy, R.; Murray-Rust, P. J. Am. Chem. Soc. 1986, 108, 4308-4314.

(7) (a) Hassel, O.; RØmming, C. Quart. Rev. (London) 1962, 16, 1-18. (b) Hassel, O. Science 1970, 170, 497-502.

(8) (a) Sarma, J. A. R. P.; Allen, F. H.; Hoy, V. J.; Howard, J. A. K; Thaimattam, R; Biradha, K.; Desiraju, G. R. Chem. Commun. 1997, 101-102. (b) Bond, A. D.; Griffiths, J.; Rawson, J. M.; Hulliger, J. Chem. Commun. 2001, 2488-2489. (c) Thallapally, P. K.; Desiraju, G. R; Bagieu-Beucher, M.; Masse, R; Bourgogne, C.; Nicoud, J. F. Chem. Commun. 2002, 1052-1053. (d) George, S.; Nangia, A.; Lam, C.-K; Mak, T. C.W.; Nicoud, J.-F. Chem. 
Commun. 2004, 1202-1203. (e) Metrangolo, P.; Resnati, G.; Meyer, F.; Pilati, T.; Liantonio, R; Meyer, F. J. Polym. Sci., Part A: Polym. Chem. 2007, $45,1-15$ and references therein.

(9) Metrangolo, P.; Resnati, G. Chem.-Eur. J. 2001, 7, 2511-2519. (b) Gonnade, R. G.; Shashidhar, M. S.; Bhadbhade, M. M. J. Indian Inst. Sci. 2007, 87, 149-165. (c) Metrangolo, P.; Meyer, F.; Pilati, T.; Resnati, G.; Terraneo, G. Angew. Chem. Int. Ed. 2008, 47, 6114-6127. (d) Cavallo, G.; Metrangolo, P.; Pilati, T.; Resnati, G.; Sansotera, M.; Terraneo, G. Chem. Soc. Rev. 2010, 39, 3772-3783.

(10) Auffinger, P.; Hays, F. A.; Westhof, E.; Ho, P. S. Proc. Natl. Acad. Sci. U.S.A. 2004, 101, 16789-16794 and references therein.(b) Voth, A. R; Hays, F. A.; Ho, P. S. Proc. Natl. Acad. Sci. U.S.A. 2007, 104, 1688-6193. (c) Tawarada, R; Seio, K; Sekine, M. J. Org. Chem. 2008, 73, 383-390.

(11) Sureshan, K. M.; Gonnade, R. G.; Puranik, V. G.; Bhadbhade, M. M.; Shashidhar, M. S. Chem. Commun. 2001, 881-882. (b) Caronna, T.; Liantonio, R.; Logothetis, T. A.; Metrangolo, P.; Pilati, T.; Resnati, G. J. Am. Chem. Soc. 2004, 126, 4500-4501. (c) Gonnade, R. G.; Bhadbhade, M. M.; Shashidhar, M. S.; Sanki, A. K. Chem. Commun. 2005, 5870-5872. (d) Saha, B. K.; Nangia, A.; Jaskolski, M. CrystEngComm. 2005, 7, 355-358. (e) Aakeroy, C. B.; Fasulo, M.; Schultheiss, N.; Desper, J.; Moore, C. J. Am. Chem. Soc. 2007, 129, 13772-13773. (f) Gonnade, R. G.; Bhadbhade, M. M.; Shashidhar, M. S. CrystEngComm. 2008, 10, 288-296.

(12) (a) Farina, A.; Meille, S. V.; Messina, M. T.; Metrangolo, P.; Resnati, G.; Vecchio, G. Angew. Chem. Int. Ed. 1999, 38, 2433-2436. (b) Takeuchi, T.; Minato, Y.; Masayoshi, M.; Shinmori, H. Tetrahedron Lett. 2005, 46, 9025-9027.

(13) Jiang, Y.; Alcaraz, A. A.; Chen, J. M.; Kobayashi, H.; Lu, Y. J.; Snyder, J. P. J. Med. Chem. 2006, 49, 1891-1899.

(14) (a) Bertani, R.; Metrangolo, P.; Moiana, A.; Perez, E.; Pilati, T.; Resnati, G.; Rico-Lattes, I.; Sassi, A. Adv. Mater. 2002, 14, 1197-1201. (b) Xu, J.; Liu, X.; Lin, T.; Huang, J.; He, C. Macromolecules 2005, 38, 3554-3557. (c) Metrangolo, P.; Prasang, C.; Resnati, G.; Liantonio, R.; Whitwood, A. C.; Bruce, D. W. Chem. Commun. 2006, 3290-3292.

(15) (a) Metrangolo, P.; Meyer, F.; Pilati, T.; Proserpio, D. M.; Resnati, G. Cryst. Growth Des. 2008, 8, 654-659. (b) Raatikainen, K.; Rissanen, K. CrystEngComm. 2009, 11, 750-752.

(16) (a) Imakubo, T.; Sawa, H.; Kato, R. Synth. Met. 1995, 73, 117-122. (b) Fourmigue, M.; Batail, P. Chem. Rev. 2004, 104, 5379-5418. (c) Yamamoto, H. M.; Kosaka, Y.; Maeda, R.; Tamura, J.; Nakao, A.; Nakamura, T.; Kato, R. ACS Nano 2008, 2, 143-155.

(17) (a) Coppens, P. X-ray Charge Densities and Chemical Bonding; Oxford University Press: Oxford, U.K., 1997. (b) Koritsanszky, T. S.; Coppens, P. Chem. Rev. 2001, 101, 1583-1621.

(18) (a) Bader., R. F. W. Atoms in Molecules-A Quantum Theory; Clarendon: Oxford, U.K., 1990. (b) Bader., R. F. W. J. Phys. Chem. A 1998, 102, 7314-7323.

(19) (a) Duarte, D. J. R.; de las Vallejos, M. M.; Peruchena, N. M. J. Mol. Model. 2010, 16, 737-748. (b) Amezaga, N. J. M.; Pamies, S. C.; Peruchena, N. M.; Sosa, G. L. J. Phys. Chem. A 2010, 114, 552-562.

(20) (a) Cody, V.; Murray-Rust, P. J. Mol. Struct. 1984, 112, 189-199. (b) Lommerse, J. P. M.; Stone, A. J.; Taylor, R.; Allen, F. H. J. Am. Chem. Soc. 1996, 118, 3108-3116. (c) Brammer, L.; Bruton, E. A.; Sherwood, P. Cryst. Growth Des. 2001, 1, 277-290. (d) Ouvrard, C.; Le Questel, J. Y.; Berthelot, M.; Laurence, C. Acta Crystallogr., Sect. B 2003, 59, 512-526. (e) Metrangolo, P.; Neukirch, H.; Pilati, T.; Resnati, G. Acc. Chem. Res. 2005, 38, 386-395. (f) Rissanen, K. CrystEngComm. 2008, 10, 1107-1113.

(21) (a) Hathwar, V. R.; Row, T. N. G. J. Phys. Chem. A 2010, 114, 13434-13441.(b) Hathwar, V. R.; Row, T. N. G. Cryst. Growth Des. 2011, DOI: $10.1021 / \operatorname{cg} 1015862$.

(22) Bui, T. T. T.; Dahaoui, S.; Lecomte, C.; Desiraju, G. R.; Espinosa, E. Angew. Chem. Int. Ed. 2009, 48, 3838-3841.

(23) (a) Bianchi, R.; Forni, A.; Pilati, T. Chem.-Eur. J. 2003, 9, 1631-1638. (b) Bianchi, R.; Forni, A.; Pilati, T. Acta Crystallogr., Sect. B 2004, 60, 559-568.

(24) Forni, A. J. Phys. Chem. A 2009, 113, 3403-3412.

(25) Eskandari, K.; Zariny, H. Chem. Phys. Lett. 2010, 492, 9-13.
(26) Bruker APEX2 (Version 1.0.22), BIS (Version 1.2.08), COSMO (Version 1.48), and SAINT (Version 7.06A); Bruker AXS Inc.:Madison, WI, 2006.

(27) Blessing, R. H. J. Appl. Crystallogr. 1997, 30, 421-426.

(28) Sheldrick, G. M. Acta Crystallogr., Sect. A 2008, 64, 112-122.

(29) Farrugia, L. J. J. Appl. Crystallogr. 1999, 32, 837-838.

(30) Volkov, A.; Macchi, P.; Farrugia, L. J.; Gatti, C.; Mallinson, P. R.; Richter, T.; Koritsanszky, T. S. XD2006, Rev. 5.34; University at Buffalo, State University of New York: Buffalo, NY, 2006.

(31) Hansen, N. K.; Coppens, P. Acta Crystallogr., Sect. A 1978, 34, 909-921.

(32) Allen, F. H. Acta Crystallogr., Sect. B 1986, 42, 515-522.

(33) (a) Sorensen, H. O.; Stewart, R. F.; McIntyre, G. J.; Larsen, S. Acta Crystallogr., Sect. A 2003, 59, 540-550. (b) Munshi, P.; Cameron, E.; Row, T. N. G.; Ferrara, J. D.; Cameron, T. S. J. Phys. Chem. A 2007, $111,7888-7897$.

(34) (a) Madsen, A. Ø. J. Appl. Crystallogr. 2006, 39, 757-758. (b) Munshi, P.; Madsen, A. Ø.; Spackman, M. A.; Larsen, S.; Destro, R. Acta Crystallogr., Sect. A 2008, 64, 465-475.

(35) Dovesi, R.; Saunders, V. R.; Roetti, C.; Orlando, R.; ZicovichWilson, C. M.; Pascale, F.; Civalleri, B.; Doll, K.; Harrison, N. M.; Bush, I. J.; D'Arco, Ph.; Llunell, M. CRYSTAL06 User's Manual; University of Torino: Torino, Italy, 2006.

(36) (a) Lee, C.; Yang, W.; Parr, R. G. Phys. Rev. B 1988, 37, 785-789. (b) Becke, A. D. J. Chem. Phys. 1993, 98, 5648-5652.

(37) Rees, P. B. Acta Crystallogr., Sect. B 1970, 26, 1304-1311.

(38) (a) McKinnon, J. J.; Spackman, M. A.; Mitchell, A. S. Acta Crystallogr., Sect. B 2004, 60, 627-668. (b) Spackman, M. A.; McKinnon, J. J. CrystEngComm 2002, 4, 378-392.

(39) Wolff, S. K.; Grimwood, D. J.; McKinnon, J. J.; Jayatilaka, D.; Spackman, M. A. CrystalExplorer 2.0; University of Western Australia: Perth, Australia, 2007 (http://hirshfeldsurface.net/CrystalExplorer).

(40) (a) McKinnon, J. J.; Jayatilaka, D.; Spackman, M. A. Chem. Commun. 2007, 3814-3816. (b) Munshi, P.; Skelton, W.; McKinnon, J. J.; Spackman, M. A. CrystEngComm 2008, 10, 197-206. (c) Munshi, P.; Jelsch, C.; Hathwar, V. R.; Row, T. N. G. Cryst. Growth Des. 2010, $10,1516-1526$.

(41) Hirshfeld, F. L. Acta Crystallogr., Sect. A 1976, 32, 239-244.

(42) (a) Abramov, Y. A. Acta Crystallogr., Sect. A 1997, 53, 264-272. (b) Espinosa, E.; Molins, E.; Lecomte, C. Chem. Phys. Lett. 1998, 285, 170-173. (c) Espinosa, E.; Alkorta, I.; Elguero, J.; Molins, E. J. Chem. Phys. 2002, 117, 5529-5542.

(43) (a) Abramov, Y.; Volkov, A.; Wu, G.; Coppens, P. Acta Crystallogr., Sect. A 2000, 56, 585-591. (b) Abramov, Y.; Volkov, A.; Wu, G.; Coppens, P. J. Phys. Chem. B 2000, 104, 2183-2188.

(44) (a) Cox, S. R.; Hsu, L. Y.; Williams, D. E. Acta Crystallogr., Sect. A 1981, 37, 293-301. (b) Williams, D. E.; Cox, S. R. Acta Crystallogr., Sect. B 1984, 40, 404-417.

(45) (a) Presti, L. L.; Destro, R. J. Chem. Phys. 2008, 128, 044710-044718. (b) de Vries, R. Y.; Feil, D.; Tsirelson, V. G. Acta Crystallogr., Sect. B 2000, 56, 118-123. (c) Bytheway, I.; Chandler, G. S.; Figgis, B. N. Acta Crystallogr., Sect. A 2002, 58, 451-459. (d) Volkov, A.; Abramov, Y.; Coppens, P.; Gatti, C. Acta Crystallogr., Sect. A 2000, 56, 332339. (e) Coppens, P.; Volkov, A. Acta Crystallogr., Sect. A 2004, 60, $357-364$.

(46) Hubschle, C. B.; Luger, P. J. Appl. Crystallogr. 2006, 39, 901-904.

(47) (a) Politzer, P.; Lane, P.; Concha, M. C.; Ma, Y.; Murray, J. S. J. Mol. Model. 2007, 13, 305-311. (b) Murray, J. S.; Lane, P.; Clark, T.; Politzer, P. J. Mol. Model. 2007, 13, 1033-1038. (c) Clark, T.; Hennemann, M.; Murray, J, S.; Politzer, P. J. Mol. Model. 2007, 13, 291-296. (d) Murray, J. S.; Lane, P.; Politzer, P. Int. J. Quantum Chem. 2007, 107, 2286-2292. (e) Murray, J. S.; Concha, M. C.; Lane, P.; Hobza, P.; Politzer, P. J. Mol. Model. 2008, 14, 699-704. (f) Politzer, P.; Murray, J. S.; Concha, M. C. J. Mol. Model. 2008, 14, 659-665.

(48) Riley, K. E.; Hobza, P. J. Chem. Theory Comput. 2008, 4, 232-242. 